Testing abundance-range size relationships in European carabid beetles (Coleoptera, Carabidae).

Kotze, D.J.

Blackwell

2003

Kotze, D.J. et al. 2003. Testing abundance-range size relationships in European carabid pÿbeetles (Coleoptera, Carabidae). Ecography 26: 553566.

http://hdl.handle.net/1975/283

Downloaded from Helda, University of Helsinki institutional repository.

This is an electronic reprint of the original article.

This reprint may differ from the original in pagination and typographic detail.

Please cite the original version. 


\title{
Testing abundance-range size relationships in European carabid beetles (Coleoptera, Carabidae)
}

\author{
D. Johan Kotze, Jari Niemelä, R. Bob O’Hara and Hans Turin
}

Kotze, D. J., Niemelä, J., O’Hara, R. B. and Turin, H. 2003. Testing abundancerange size relationships in European carabid beetles (Coleoptera, Carabidae). Ecography 26: $553-566$.

\begin{abstract}
Four of the eight hypotheses proposed in the literature for explaining the relationship between abundance and range size (the sampling artifact, phylogenetic non-independence, range position and resource breadth hypotheses) were tested by using atlas data for carabid beetles (Coleoptera, Carabidae) from Belgium, Denmark and the Netherlands. A positive relationship between abundance and partial range size was found in all three countries, and the variation in abundance was lower for widespread species. Analysis of the data did not support three of the proposed hypotheses, but did support the resource breadth hypothesis (species having broader environmental tolerances and being able to use a wider range or resources will have higher local densities and be more widely distributed than more specialised species). Examination of species' characteristics revealed that widespread species are generally large bodied, generalists (species with wide niche breadths occurring in a variety of habitat types) and are little influenced by human-altered landscapes, while species with restricted distributions are smaller bodied, specialists (species with small niche breadths occurring in only one or two habitat types), and favour natural habitat. Landscape alteration may be an important factor influencing carabid abundance and range size in these three countries with a long history of human-induced environmental changes.
\end{abstract}

D. J. Kotze (johan.kotze@helsinki.fi), J. Niemelä and R. B. O'Hara, Dept of Ecology and Systematics, P. O. Box 65, FIN-00014, Univ. of Helsinki, Finland. - H. Turin, Dept of Plant Population Biology, Netherlands Inst. of Ecology (NIOO-KNAW), P. O. Box 40, NL-6666 ZG, The Netherlands.

The average abundance and range size of species are intimately linked. Almost without exception, locally abundant species are widespread, while locally rare species tend to be narrowly distributed (Brown 1984, Lawton 1993, 1994, Gaston 1994, 1996). A flurry of interest resulted in eight mechanisms being suggested to explain this relationship (Griffiths 1998, Johnson 1998, Gaston et al. 1998), none of which has unequivocal support (Gaston and Lawton 1990, Gaston et al. 1997a, b). These proposed mechanisms can be divided into two categories, artifactual and biological. Although the sampling artifact model has been used to explain some cases (Brown 1984, Hanski et al. 1993), Gaston et al. (1997b) have argued that in other data sets the positive abundance-range size relationship is a real pattern.
Data quality is an important consideration when investigating abundance-range size relationships (Gaston and Blackburn 1996, Blackburn and Gaston 1998). Typically, information on geographic ranges of species is unavailable, and distribution maps are often inaccurate (Gaston 1990, Högmander and Møller 1995), party because the nature of many distribution maps is dictated by collectors' home ranges, species hot spots and political boundaries. Thus, it is unclear to what extent inferences can be made at different spatial scales (Gaston 1990, Dennis and Thomas 2000). Furthermore, both abundance and range size are dynamic, whereas many atlas studies are built on the accumulation of observations over long periods of time, thereby obscuring any dynamics (Hanski et al. 1993). It is difficult to

Accepted 10 March 2003

Copyright (C) ECOGRAPHY 2003

ISSN 0906-7590

ECOGRAPHY 26:5 (2003) 
envisage means of solving the data quality problem, although there has been some progress in this area (Högmander and Møller 1995). Nevertheless, Gaston (1990) argued that species range patterns are generally robust and appear to be unaffected by either scale or collecting method (see Gregory and Blackburn 1998).

In this paper we test four of the eight mechanisms proposed for explaining the abundance-range size relationship: the sampling artifact, phylogenetic-non independence, range position and resource breadth hypotheses. We used comprehensive atlas data for ground beetles (Coleoptera, Carabidae) from Belgium, Denmark and the Netherlands.

\section{The data, hypotheses and statistical analyses}

Carabid atlases available for Belgium (Desender 1986a, b, c, d), Denmark (Bangsholt 1983) and the Netherlands (Turin 2000) provide information on the number of grid cells within the country occupied by a species, i.e. the area of occupancy (Gaston 1991), the number of records per species, species characteristics, and the position of species in relation to their European distribution (central or marginal). Belgian and Dutch grid cells were $10 \times 10 \mathrm{~km}$, while Danish grid cells were $9 \times 8 \mathrm{~km}$. With an appropriately sized grid system most species will occupy more than one grid cell (Simpson 1964), and this condition was satisfied here. Here, range size is measured as the area of occupation in part of the European distribution of the species, rather than as the total area within which a species may occur.

The abundance of a species in a country was determined by counting the number of records of that species recorded in the atlas. Specimens of the same species, captured on a given day at the same site were counted as a single record, while specimens of the same species captured at different sites in the same grid cell, at the same site on different days, or in different grid cells, were counted as separate records (Turin 2000). Carabid beetles are mainly collected by pitfall trapping, with this being supplemented by hand collecting (Lövei and Sunderland 1996, Turin 2000). Both methods may bias the data, for example pitfall traps will over-sample the more ground-active species. These biases will only be problematical for the analysis if they are correlated with the explanatory variables investigated. One clear example of this is the tolerance of species towards human environments (see below), because collectors are more likely to collect insects in their own home range.

The average abundance for each species was calculated by dividing the number of records by the number of grid cells in which the species was present. This approach avoids artifactual positive relationships be- tween abundance and range size resulting from the progressively greater contribution of zero abundance values to the mean abundances of species occurring at fewer and fewer sites (Gaston 1996). With such data it is possible to determine and compare the abundancerange size relationships for each of the three countries, and to test the ability of the following four proposed mechanisms to explain these relationships.

\section{The sampling artifact hypothesis}

This hypothesis suggests that some grid cells are incorrectly marked as not being occupied by a species even though it was present. The effect of this is that range is underestimated (as some cells are occupied, but scored as empty), and average abundance is overestimated (as the number of observations - the number of occupied grid cells - is underestimated). One way to correct for this is to fit a model of the distribution of abundances, and use this to infer the number of grid cells in which a species occurs, but was not collected. A simple model would be a Poisson distribution, however, Hanski et al. (1993) argued that it is of little practical value as nearly all species show an aggregated spatial distribution at all spatial scales, and that a negative binomial distribution would be more appropriate.

For the Dutch data only, the distribution of records per grid cell was available. From this a truncated distribution (i.e. a distribution where the class of observations with no individuals is excluded) could be fitted and then used to estimate the expected number of grid cells in which the species is present, but not recorded. Initially, two distributions were fitted by maximum likelihood: a truncated Poisson distribution (Venables and Ripley 1999) and a truncated negative binomial distribution (Sampford 1955). However, these distributions did not fit well to the data, an examination of which suggested that the number of grid cells in which a single recording was made was larger than might be expected. This pattern could occur if for some grid cells, collectors were recording the presence of a species in the grid and then not recording further occurrences of the species. In order to account for this, we fitted a mixture distribution consisting of a truncated Poisson (or negative binomial) distribution augmented by an extra term for the probability of observing a single record. The number of observations of a single record was therefore modelled so that a proportion is due to the Poisson (or negative binomial) distribution and the rest are the single records, where collectors did not report the species after the original report.

Augmented truncated Poisson and negative binomial distributions were fitted to the data by treating the proportion of observations of a single record arising from the Poisson (or negative binomial) part of the 
distribution as missing data, and then estimating this proportion using an EM algorithm (Dempster et al. 1977). The EM algorithm works by iterating between two steps. Firstly, the maximum likelihood estimates of the parameters are found, given an estimate of the number of single records from the Poisson (or negative binomial) distribution. Then, the number of single records from the Poisson (or negative binomial) distribution is re-estimated, given the maximum likelihood estimates of the parameters. This is continued until the estimates converge. The corrected abundance was then regressed against the corrected range size, using the corrected range size as a weight (to overcome the problem that the variance decreases with increasing range size; see Fig. 1).
The phylogenetic non-independence hypothesis

This hypothesis predicts that there will be no abundance-range size relationship once the effects of phylogenetic relatedness among species has been removed (Gaston et al. 1997b). According to this hypothesis both range size and local abundance are constrained and determined by phylogeny, meaning that there is less variation in abundance and range size within congeneric species than between them (Lawton 1993). Controlling for this effect by examining relationships within each pair of taxa below a node in a bifurcating phylogeny (Gaston et al. 1997a) was not possible as it requires a known phylogeny, which is not available for species of European carabid beetles (see Maddison et
Fig. 1. The relationship between abundance and partial range size for carabid species in Belgium, Denmark and the Netherlands.

Symbols: $\bullet=$ range edge species, $\bigcirc=$ species with a more central distribution in the country involved.
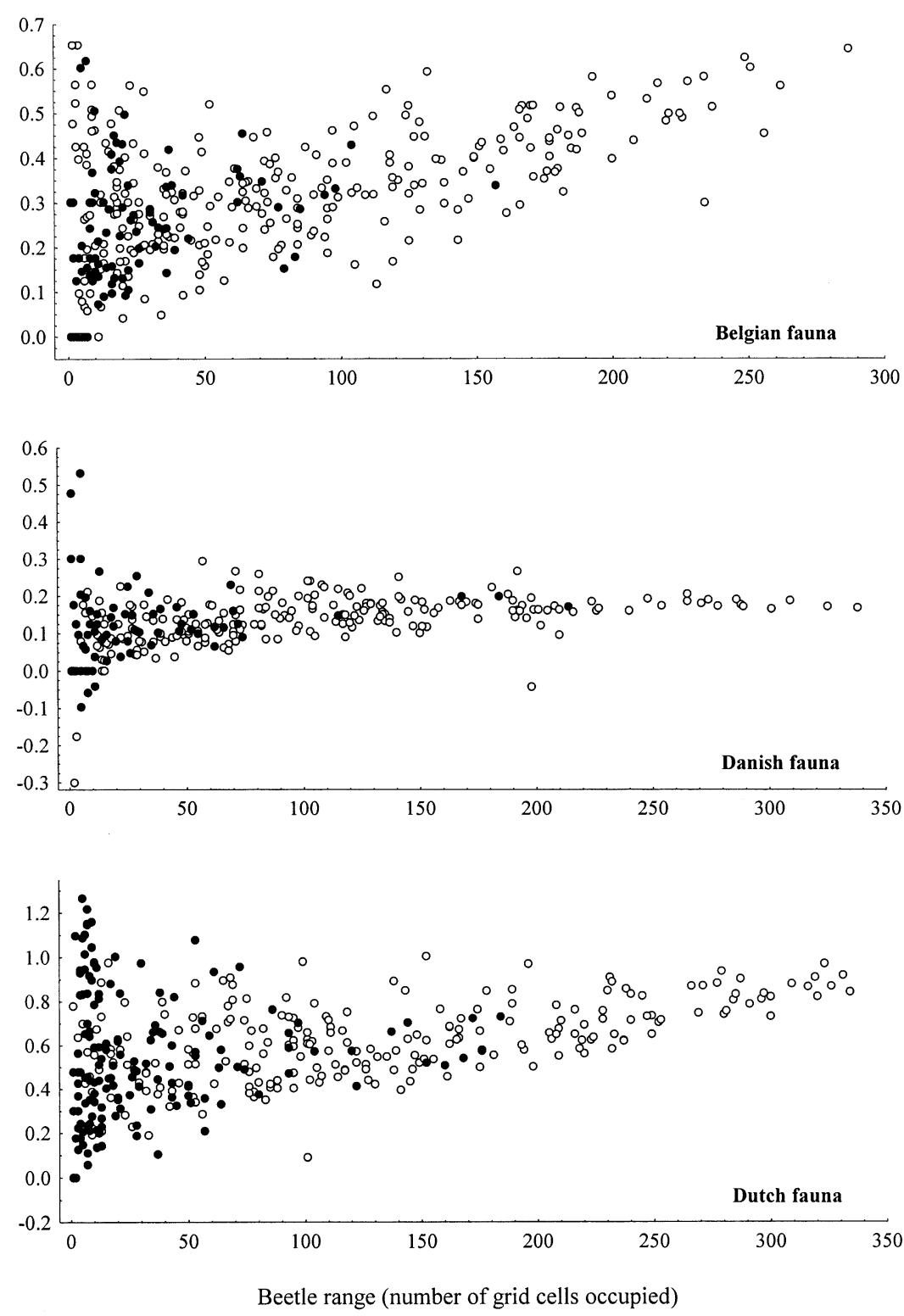
al. 1999). Instead, the genus of the species was entered into our models as a factor before range size, thereby removing the inter-genus effect first. Individual genera are considered to be relatively free of phylogenetic constraints (Harvey and Pagel 1991).

\section{The range position hypothesis}

This hypothesis predicts that a positive abundancerange size relationship can result from a species' geographic position. If the abundance of a species declines towards the edges of its geographic range and the species only occupies a small proportion of the study area in the edges of its range, then a positive relationship between abundance and range size can result (Gaston et al. 1997b). Here, range central and range edge carabids were defined visually by using the European distribution maps in Turin (2000), and from range central-range edge classifications in the literature (Desender 1986a, b, c, d, Turin and Den Boer 1988, Desender and Turin 1989). A carabid species was classified as a range edge species when its European distribution ends within the country investigated and when it is clear that the centre of a species' range is outside the country investigated (see Fig. 2 in Hengeveld and Haeck 1982, Desender and Turin 1989).

Weighted least squares regression was used (Draper and Smith 1998) to test the effects of both phylogeny and range position on the abundance-range size relationships, with range size being used as a weight, as above. Factors were entered into the analysis sequentially, entering range position (central or edge) and genus $\quad($ Belgium $=65$ genera; Denmark $=57$; The Netherlands = 67) first, and then entering Grids into the model. The Grids effect should be interpreted as the effect of Grids after the range position and genus effects have been taken into account. If the relationship was caused by either of these characteristics, range size would not be a good predictor of abundance after these factors had been included in the model.

\section{The resource breadth hypothesis}

The resource breadth hypothesis suggests that species having broader environmental tolerances and being able to use a wider range of resources will have higher local densities and be more widely distributed than more specialised species (Brown 1984). In other words, generalists are both widely distributed and locally abundant, while specialists are geographically restricted and have low average abundance (Hanski et al. 1993). Carabid ecological specialisation is defined along a continuum from strict specialists (species with small niche breadths occurring in only one or two habitat types) to generalists (species with wide niche breadths occurring in a variety of habitat types) (Dufrêne and Legendre 1997). Although this definition attempts to clarify carabid specialisation, in reality it is not that straightforward as the term is traditionally defined quite loosely. For instance, even though habitat affinity is the main criterion, temperature, $\mathrm{pH}$, light, soil and other microhabitat preferences are also taken into account (Thiele 1977, J. Spence, L. Penev, K. Desender pers. comm.). The specialisation classifications obtained from the literature (see Table 1) are a function of a number of characteristics, some of which were difficult to quantify.

Furthermore, the reasoning may be circular, as the measurement of ecological specialisation may not be strictly independent of abundance or range size (Hanski et al. 1993). Species found within small areas or only rarely collected are usually regarded as specialists,

Table 1. Carabid characteristics* used in the Generalized Linear Model. For visual purposes, both body size and specialisation were categorised (see Fig. 3), but were treated as variates in the models due to their continuous nature.

\begin{tabular}{|c|c|c|c|c|}
\hline \multicolumn{5}{|c|}{ Carabid characteristic } \\
\hline \multicolumn{3}{|c|}{ Factors } & \multicolumn{2}{|r|}{ Variates } \\
\hline Habitat & $\mathrm{N}_{-} \mathrm{H}$ & Wings & Body size & Specialisation $\left(\mathrm{S} \_\mathrm{G}\right)$ \\
\hline Wet woodlands & Natural & Macropterous (M) & $0-2.9 \mathrm{~mm}$ & Strict specialist $(\mathrm{S})$ \\
\hline Dry woodlands & Human & Dimorphic (D) & $3-4.9 \mathrm{~mm}$ & Average specialist (S-avg) \\
\hline Wet many & & Brachypterous (B) & $5-8.9 \mathrm{~mm}$ & Average speciality (Avg) \\
\hline Dry many & & & $9-16.9 \mathrm{~mm}$ & Average generalist (G-avg) \\
\hline Wet open & & & $>16.9 \mathrm{~mm}$ & Strict generalist $(\mathrm{G})$ \\
\hline Dry open & & & & \\
\hline Wet grasslands & & & & \\
\hline Dry grasslands & & & & \\
\hline Riparian & & & & \\
\hline Bogs & & & & \\
\hline Wet coastal & & & & \\
\hline Dry coastal & & & & \\
\hline
\end{tabular}

* Data obtained from Bangsholt (1983), Lindroth (1985, 1986), Desender (1986a, b, c, d), Turin and Den Boer (1988), Turin and Heijerman (1988), Desender and Turin (1989), Turin (2000). 
whilst widespread and abundant species are likely to be studied more thoroughly, giving a skewed view of resource use by common species compared to rare ones. Nevertheless, we are confident that for carabid beetles, ecological specialisation is reasonably independent of abundance and range size, for two reasons. First, carabid ecological specialisation is primarily defined on the basis of habitat affinity and other microhabitat preferences (see above), and second, both professional and amateur collectors have been thorough in collecting carabid beetles in western Europe.

The resource breadth hypothesis can be tested by 1) showing that carabid generalists are more abundant and widespread than are specialists, and by 2) showing that carabids associated with human environments are more abundant and widespread than those that are not (this second test assumes that carabids found in human environments have, on average, broader environmental tolerances than species not typically found in human environments).

Three other carabid characteristics were analysed to determine if any of these contribute to the observed abundance-range size patterns, and, in particular, to examine their effects on ecological specialisation. These characteristics include length of flight wings (species with short, long or dimorphic wing forms), body size in millimetres, and habitat association (Table 1). Habitat association is defined as the habitat type the species most frequently occurs in (Turin 2000). It is weakly related to ecological specialisation because species associated with many habitat types are likely to be generalists, and those associated with one or a few habitat types are likely to be specialists (Table 1). However, a carabid specialist (most species) can be associated with either woodland, grassland, riparian or coastal habitat types. By changing the order in which specialisation and habitat association are entered into a regression model, we can examine the extent to which each one explains the pattern observed.

In testing the resource breadth hypothesis a generalized linear model (McCullagh and Nelder 1989) was used to investigate the relationships between the carabid characteristics and range size in each country. The number of grid cells occupied by each species was modelled as a binomial distribution, with the explanatory variables included via a logit link function. Because of large residual deviances (overdispersion) the variance of each factor was compared to the residual deviance, which approximately follows an F-distribution under the null hypothesis that the factor does not have an effect. Spatial dependence between neighbouring grid cells is ignored in this analysis, even though it is likely to be present in this type of data (Högmander and Møller 1995). However, the results of the significance tests are clear enough so as to be robust to some bias in the estimation error variation.
The full model had habitat association, human environments and wing form as factors, and body size and ecological specialisation as variates, with main effects and first order interactions included. Additionally, we regressed these five characteristics against abundance in an attempt to unravel the effect of ecological specialisation on abundance.

Four hypotheses proposed for explaining abundancerange size relationships could not be tested using our atlas data, mainly because there is not enough information available. These include the resource availability, the habitat selection, the metapopulation dynamics and the vital rates hypotheses. For more details on these hypotheses, see Gaston et al. (1997b).

\section{Results}

According to the atlases, 379 carabid species were present in Belgium, 314 in Denmark and 380 in the Netherlands. Belgium and Denmark had 267 species in common, Belgium and the Netherlands 330, Denmark and the Netherlands 291, and all three countries shared 264 species. The number of species at the edge of their distribution was similar in Belgium ( 92 species, $24 \%$ of the species) and Denmark (87 species, 28\%), but higher in the Netherlands (157 species, 41\%).

Carabid faunas of each of the three countries showed significant positive abundance-range size relationships (Table 2, Fig. 1). However, the variance in mean abundance decreased with increasing range size (the relationship is "heteroscedastic"). The residuals appeared to be normally distributed, with only an occasional outlier (Table 2).

Even after fitting a range of different distributions to the Dutch data, the abundance-range size relationship was still significantly positive (Fig. 2). Indeed, the estimate of the slope was robust to most of the models, with the exception of the truncated negative binomial distribution, although even then the slope was still significantly positive. As making the corrections had little effect on the magnitude of the slope, all subsequent analyses were performed on the uncorrected data sets. Analyses performed on all data sets corrected with a truncated Poisson distribution gave similar results to those for the uncorrected data sets (it was not possible to estimate the parameters of the other distributions from only the mean abundance). These analyses indicate that, at least for the Netherlands, the sampling artifact hypothesis did not explain the positive abundance-range size relationship.

After genus and range position were included in the model, range size still had a significant effect on abundance (Table 2), implying that the positive relationships between mean abundance and range size does not depend on the effects of phylogeny or range position. 
Table 2. Weighted* least-square regression testing the effect of carabid genera ${ }^{\dagger}$ (phylogenetic non-independence hypothesis) and edge species (range position hypothesis) on the abundance-range size relationship. This is a model with all interactions. Grids was included last because we wanted to test whether the other factors could cause the observed pattern, and the terms were added sequentially.

\begin{tabular}{|c|c|c|c|c|c|}
\hline Source of variation & $\mathrm{DF}$ & SS & MS & $\mathrm{F}$ & $\mathrm{p}$ \\
\hline \multicolumn{6}{|l|}{ Belgium $^{\dagger \dagger}$} \\
\hline Edge & 1 & 46.15 & 46.15 & 66.014 & $<0.001$ \\
\hline Genus & 64 & 227.70 & 3.56 & 5.089 & $<0.001$ \\
\hline Grids & 1 & 319.52 & 319.52 & 457.016 & $<0.001$ \\
\hline Edge $\times$ genus & 26 & 11.62 & 0.45 & 0.640 & 0.913 \\
\hline Edge $\times$ grids & 1 & 1.83 & 1.83 & 2.612 & 0.107 \\
\hline Genus $\times$ grids & 36 & 33.80 & 0.94 & 1.343 & 0.102 \\
\hline Edge $\times$ genus $\times$ grids & 10 & 2.38 & 0.24 & 0.341 & 0.969 \\
\hline Residuals & 239 & 167.10 & 0.70 & & \\
\hline \multicolumn{6}{|l|}{ Denmark $^{\dagger \dagger \dagger}$} \\
\hline Edge & 1 & 1.02 & 1.02 & 6.909 & 0.009 \\
\hline Genus & 56 & 14.54 & 0.26 & 1.764 & 0.003 \\
\hline Grids & 1 & 10.08 & 10.08 & 68.541 & $<0.001$ \\
\hline Edge $\times$ genus & 22 & 4.70 & 0.21 & 1.451 & 0.096 \\
\hline Edge $\times$ grids & 1 & 0.30 & 0.30 & 2.058 & 0.153 \\
\hline Genus $\times$ grids & 32 & 6.24 & 0.20 & 1.326 & 0.127 \\
\hline Edge $\times$ genus $\times$ grids & 9 & 1.50 & 0.17 & 1.136 & 0.340 \\
\hline Residuals & 190 & 27.96 & 0.15 & & \\
\hline \multicolumn{6}{|l|}{ The Netherlands } \\
\hline Edge & 1 & 195.76 & 195.76 & 40.418 & $<0.001$ \\
\hline Genus & 66 & 1415.56 & 21.45 & 4.428 & $<0.001$ \\
\hline Grids & 1 & 634.62 & 634.62 & 131.027 & $<0.001$ \\
\hline Edge $\times$ genus & 28 & 125.74 & 4.49 & 0.927 & 0.575 \\
\hline Edge $\times$ grids & 1 & 16.15 & 16.15 & 3.334 & 0.069 \\
\hline Genus $\times$ grids & 33 & 142.67 & 4.32 & 0.893 & 0.640 \\
\hline Edge $\times$ genus $\times$ grids & 16 & 87.94 & 5.50 & 1.135 & 0.324 \\
\hline Residuals & 233 & 1128.51 & 4.84 & & \\
\hline
\end{tabular}

* the number of grids was used as a weight, with abundance the dependent variable in the analysis.

$\dagger$ carabid genus name was used as a factor, so all the genera are included in the analysis.

${ }^{+\dagger}$ Bembidion femoratum was a large outlier here (with a weighted residual of ca +2.0 ), but when removed did not change the results of this test by much.

t+ Carabus granulatus was a large negative outlier here and did influence the results of this test. The results shown are without this species.

Certain genera were, however, consistently more widespread than others. For example, in all three countries, species of the genus Pterostichus were twice as widely distributed as species of the genera Bembidion or Harpalus (Table 3). Range edge species had both smaller range sizes and lower mean abundances compared to range central species (Table 4; Fig. 1).

Generalist species were significantly more widespread than specialists, and species associated with human environments were significantly more widespread than species that are not (Table 5; Figs 3 and 4), indicating that the resource breadth hypothesis is supported by the data. Furthermore, wing-dimorphic species were significantly more widespread than short or long winged species, and large-bodied carabids were significantly more widespread than small-bodied species (Tables 5 and 6; Fig. 3). Ecological specialisation and habitat association appeared to be independent measures because alternating the order in which these factors were entered into the models did not change the results (Table 5).
After range size had been taken into account, specialisation did not affect mean carabid abundance in Belgium and Denmark, but it did in the Netherlands (Table 7). However, when range size was not included in the models, carabid generalists were significantly more abundant than specialists (Belgium: $F_{1,247}=$ 29.027, $\mathrm{p}<0.001$; Denmark: $\mathrm{F}_{1,202}=12.803, \mathrm{p}<0.001$; the Netherlands: $\left.F_{1,201}=66.158, p<0.001\right)$. This is mainly because abundance and range size are significantly positively correlated (Table 2 ; Fig. 1). The main problem here is that of causality. Are carabid beetles more abundant locally because they are widespread or are they widespread because they are abundant locally? There is no simple answer to this question.

\section{Discussion}

Carabid beetles showed a significant positive relationship between abundance and range size in three European countries. This result adds to the evidence for a 


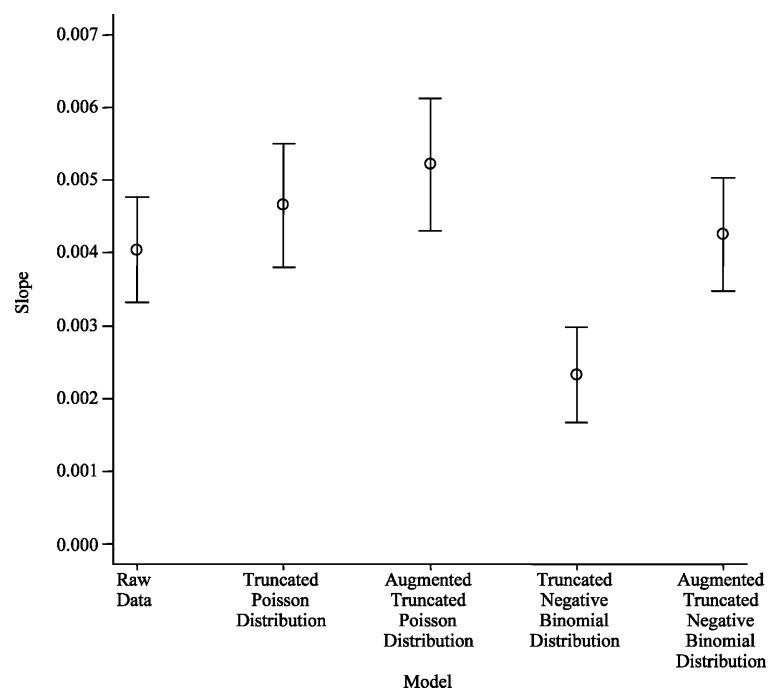

Fig. 2. Slope estimates and $95 \%$ confidence intervals for different corrections of the abundance-range size distribution. All models showed a significant positive slope, meaning that the relationship between carabid abundance and range size remained significantly positive, regardless of distribution model used.

positive relationship between abundance and range size in taxa as diverse as plants (Thompson et al. 1998), parasites of bumblebees (Durrer and Schmid-Hempel 1995), and birds and mammals (Blackburn et al. 1997, Poulin 1999). Of the four mechanisms tested, only the resource breadth hypothesis was supported by our data. However, the relationship may not have a single, universal explanation (Hanski et al. 1993, Gaston et al 1997b).
Table 4. Mean abundance and range size of central and range edge species in Belgium, Denmark and the Netherlands. SE = standard error.

\begin{tabular}{lrllll}
\hline & \multicolumn{2}{c}{ Central } & & \multicolumn{2}{c}{ Range edge } \\
\cline { 2 - 3 } Country and factor & Mean & SE & & Mean & SE \\
\hline $\begin{array}{l}\text { Belgium } \\
\quad \text { Abundance }\end{array}$ & 0.49 & 0.01 & & 0.44 & 0.01 \\
$\quad$ Range size & 76.86 & 4.02 & & 25.72 & 2.90 \\
$\begin{array}{l}\text { Denmark } \\
\quad \text { Abundance }\end{array}$ & 0.37 & 0.003 & & 0.36 & 0.01 \\
$\quad \begin{array}{l}\text { Range size } \\
\text { The Netherlands }\end{array}$ & 99.30 & 5.13 & & 26.47 & 4.10 \\
$\quad \begin{array}{l}\text { Abundance } \\
\quad \text { Range size }\end{array}$ & 0.72 & 0.01 & & 0.66 & 0.02 \\
& 129.91 & 5.96 & & 31.45 & 3.18 \\
\hline
\end{tabular}

\section{Artifactual mechanisms were not supported}

Studies of abundance-range size patterns have paid particular attention to artifactual mechanisms (Brown 1995, Gaston and Blackburn 1996, Gaston et al. 1997a, Blackburn and Gaston 1998, Pyron 1999). Although sampling error can contribute to a positive abundancerange size relationship, the relationship is not changed when using different models to correct for this error. Therefore, this error appears to be small in our study (Fig. 2), and sampling error can be discarded as an explanation for the abundance-range size patterns. Even if we cannot definitively declare limits of the geographic range as real, as Brown (1984) was able to do for North American land birds, it can at least be concluded that they are sufficiently well described so as not to affect the general conclusions.

Gaston et al. (1997a, b) stated that the phylogenetic relatedness of species has seldom been accounted for in

Table 3. Mean \pm 1 SE body size, range sizes and abundances of the six most specious carabid genera in Belgium, Denmark and the Netherlands. $\mathrm{N}=$ number of species.

\begin{tabular}{|c|c|c|c|c|}
\hline Country and genus & $\mathrm{N}$ & Mean size $(\mathrm{mm})$ & Range size & Abundance \\
\hline \multicolumn{5}{|l|}{ Belgium } \\
\hline Agonum & 23 & $7.70 \pm 0.26$ & $93.61 \pm 16.55$ & $0.50 \pm 0.02$ \\
\hline Amara & 35 & $7.96 \pm 0.28$ & $65.17 \pm 11.34$ & $0.47 \pm 0.01$ \\
\hline Bembidion & 59 & $4.33 \pm 0.15$ & $58.19 \pm 8.34$ & $0.50 \pm 0.01$ \\
\hline Carabus & 16 & $23.91 \pm 1.23$ & $101.00 \pm 17.71$ & $0.47 \pm 0.02$ \\
\hline Harpalus & 42 & $9.25 \pm 0.33$ & $44.79 \pm 8.77$ & $0.49 \pm 0.01$ \\
\hline Pterostichus & 23 & $10.76 \pm 0.70$ & $109.70 \pm 16.60$ & $0.54 \pm 0.01$ \\
\hline \multicolumn{5}{|l|}{ Denmark } \\
\hline Agonum & 22 & $7.76 \pm 0.34$ & $89.77 \pm 14.37$ & $0.37 \pm 0.01$ \\
\hline Amara & 36 & $7.88 \pm 0.28$ & $82.39 \pm 11.83$ & $0.37 \pm 0.01$ \\
\hline Bembidion & 49 & $4.01 \pm 0.14$ & $63.31 \pm 9.86$ & $0.36 \pm 0.01$ \\
\hline Carabus & 13 & $24.02 \pm 1.52$ & $90.85 \pm 16.20$ & $0.39 \pm 0.01$ \\
\hline Harpalus & 31 & $9.02 \pm 0.36$ & $68.68 \pm 16.12$ & $0.36 \pm 0.01$ \\
\hline Pterostichus & 19 & $10.41 \pm 0.75$ & $126.11 \pm 25.24$ & $0.37 \pm 0.01$ \\
\hline \multicolumn{5}{|l|}{ The Netherlands } \\
\hline Agonum & 26 & $7.82 \pm 0.29$ & $114.00 \pm 19.76$ & $0.67 \pm 0.03$ \\
\hline Amara & 36 & $7.95 \pm 0.28$ & $108.17 \pm 16.02$ & $0.68 \pm 0.03$ \\
\hline Bembidion & 58 & $4.28 \pm 0.14$ & $58.86 \pm 10.90$ & $0.70 \pm 0.02$ \\
\hline Carabus & 15 & $23.87 \pm 1.31$ & $88.40 \pm 19.58$ & $0.82 \pm 0.05$ \\
\hline Harpalus & 40 & $9.03 \pm 0.32$ & $55.70 \pm 11.67$ & $0.70 \pm 0.04$ \\
\hline Pterostichus & 23 & $10.56 \pm 0.70$ & $147.30 \pm 25.45$ & $0.79 \pm 0.04$ \\
\hline
\end{tabular}


Table 5. Generalized Linear Model results of carabid range size and the five carabid characteristics selected (N_H, wing form, body size, S_G and habitat)*. Significant results ( $\mathrm{p}$ values) are highlighted. Specialisation and habitat association were entered in alternating order into the models to test for interdependence of these two factors.

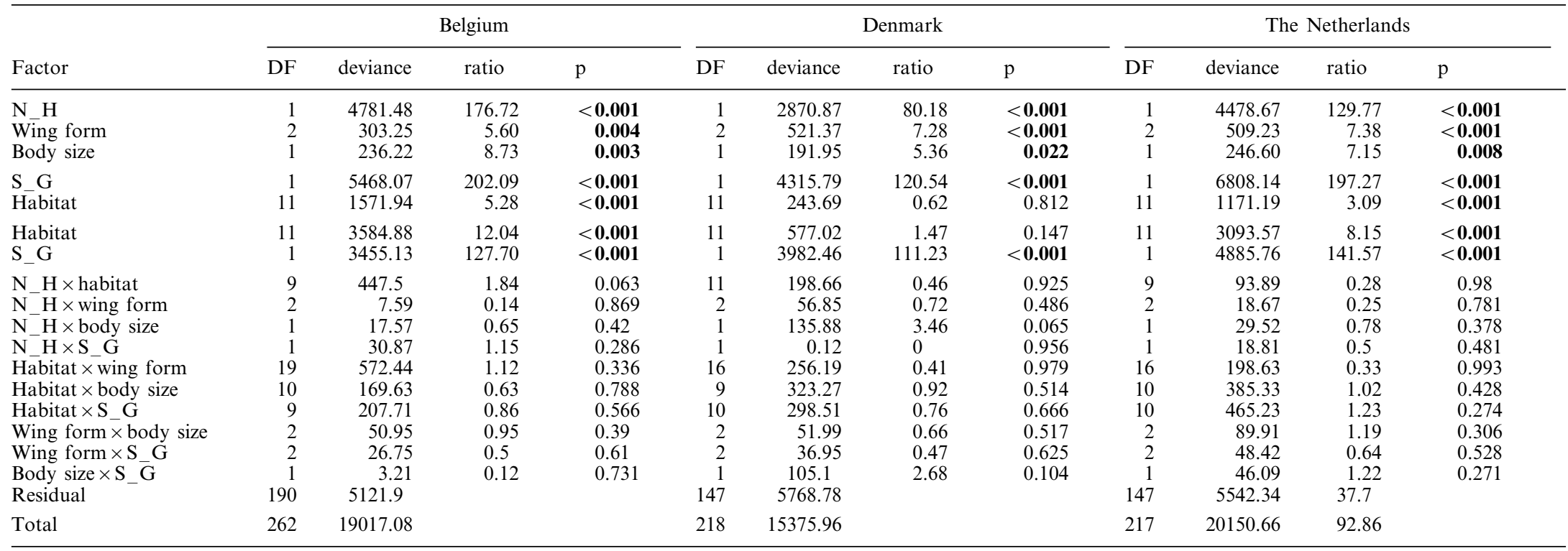

*Explanations and abbreviations (see also Table 1): N_H - whether the species occur in natural or human environments; wing form - three wing forms were identified, macropterous, dimorphic, brachypterous; body size - beetles were divided into five size categories from 0-2.9 mm to > $16.9 \mathrm{~mm}$; S_G - ecological amplitude divided into five categories from strict specialist to strict generalist; habitat - 12 habitat types were identified. 
Fig. 3. Mean range sizes ( \pm 1SE) per carabid beetle characteristic. Three

characteristics are shown

here; wing form

( $\mathrm{M}=$ macropterous,

$\mathrm{D}=$ dimorphic,

$\mathrm{B}=$ brachypterous), body size (five classes starting at $0-2.9$

$\mathrm{mm}$ to $>16.9 \mathrm{~mm}$ ) and specialisation $(\mathrm{S}=$ strict specialist, $\mathrm{S}$-avg $=$ average specialist, Avg = average speciality, G-avg = average generalist, $\mathrm{G}=$ strict generalist).

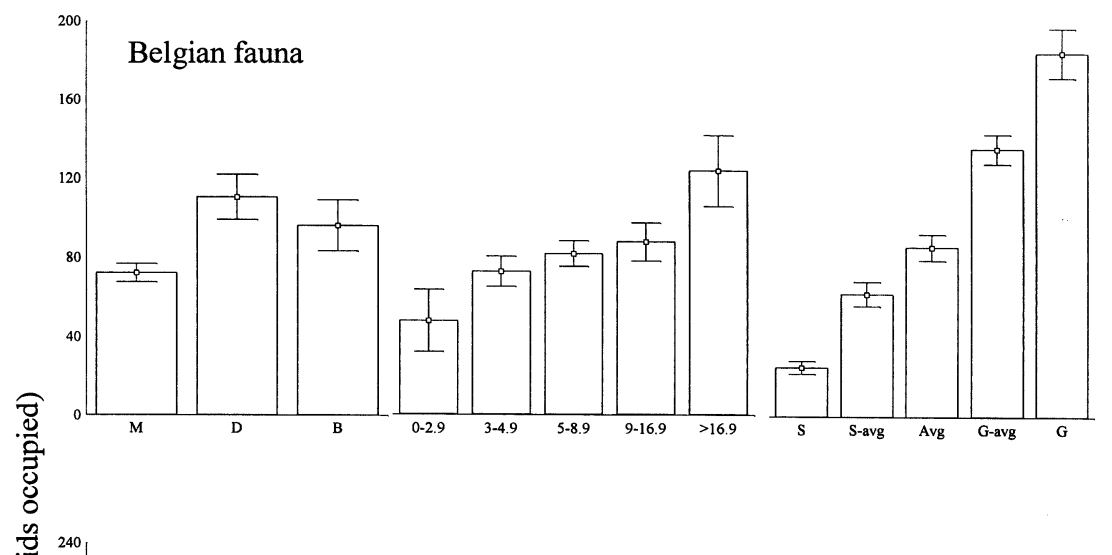

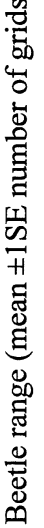

Danish fauna

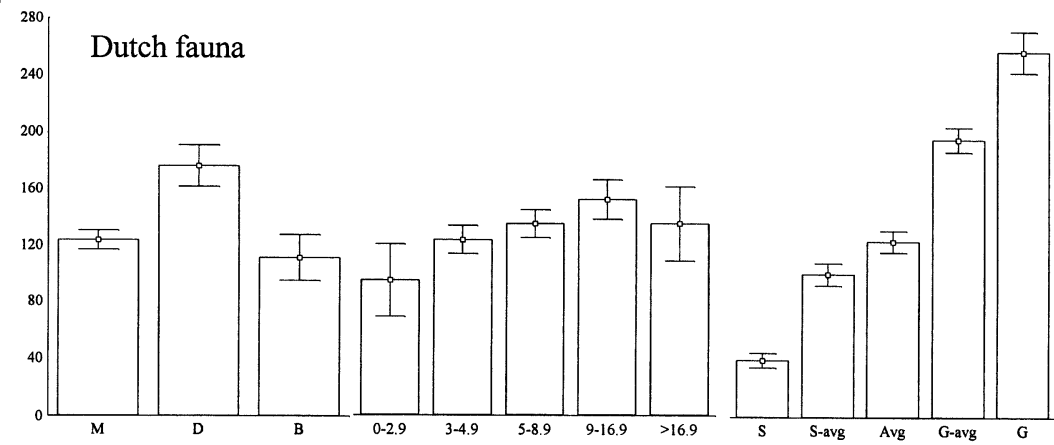

Carabid beetle characteristics

the analysis of abundance-range size relationships, but suggested that in studies where this was done, it did not affect the conclusions. Our results are in agreement with this notion, as individual genera did not contribute to the observed positive relationship between abundance and range size. Our study suggests that phylogeny cannot explain, or does not cause the positive relationship between abundance and range size.

The range position hypothesis suggests that a positive abundance-range size relationship can result from the distribution of species in relation to the area studied, i.e. the relationships observed can be an artifact dictated by political boundaries (Gaston 1990). Although significantly positive relationships were found for the three countries studied when edge species were excluded from the analyses, these relationships did not differ from those with edge species included. Therefore, the data do not support the range position hypothesis.

In terms of European geography, Belgium, Denmark and the Netherlands are at the edge of the continent, and it is not always clear whether a species is at its true distributional edge in these countries. Indeed, Blackburn et al. (1999) argue that although it is often easy to see approximately where a species' range edge lies, it is much more difficult to pinpoint the exact edge. Obvious edge species were removed from our data, but other, potential edge species could have been removed. However, it is unlikely that this would have changed the results, as that would have implied that "almost edge" species were behaving differently from edge and central 


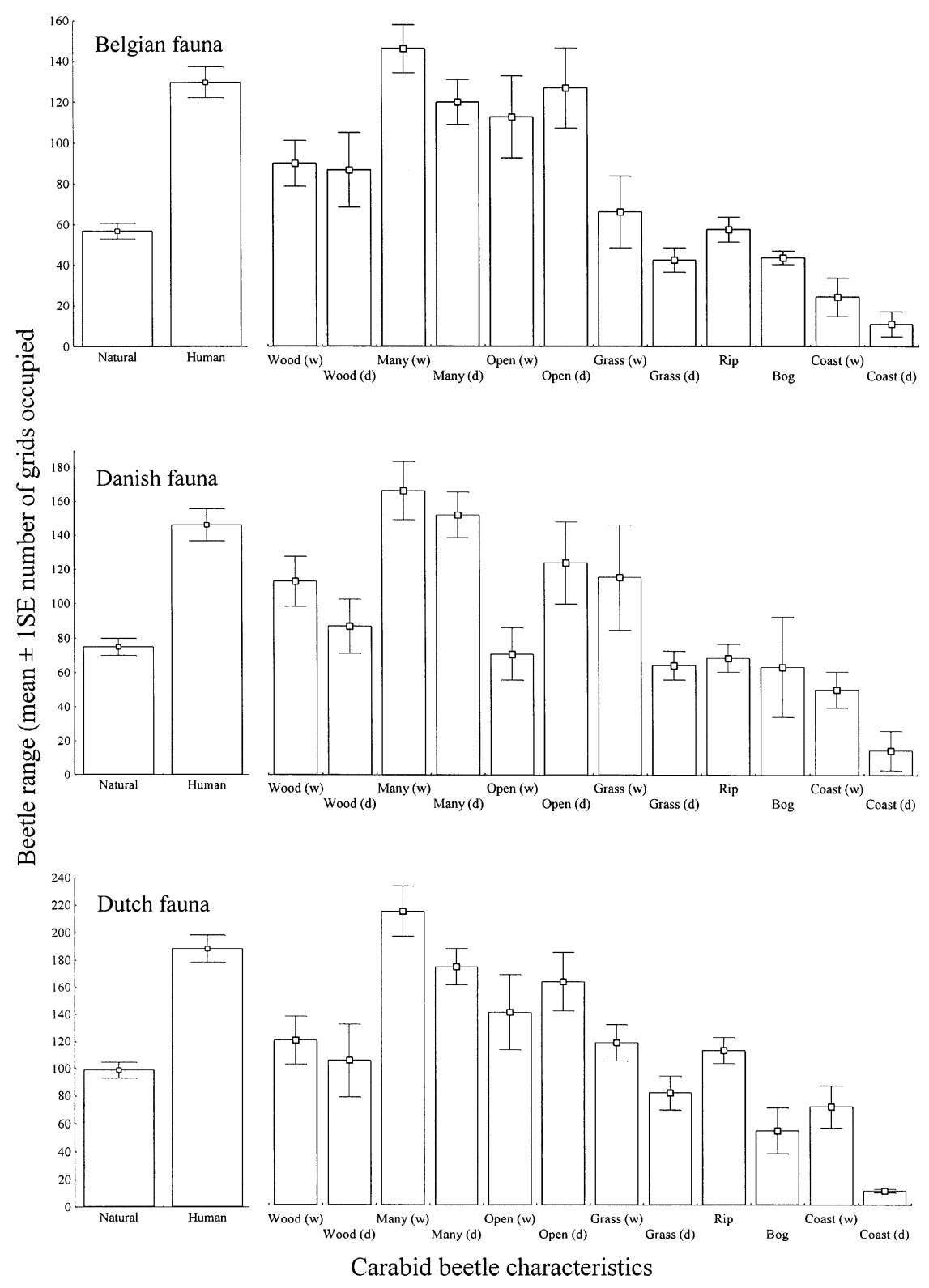

Fig. 4. Mean range sizes $( \pm 1 \mathrm{SE})$ per carabid beetle characteristic. Two

characteristics are shown here; whether a species can occur in human environments or not (natural and human) and habitat types (wet woodlands, dry woodlands, wet many, dry many, wet open, dry open, wet grasslands, dry grasslands, riparian, bogs, wet coastal and dry coastal).

species. Additional support for the rejection of the range position hypothesis comes from another prediction of the hypothesis; that the abundance-range size relationship may tend to be lower triangular, with a larger variance in abundance for more widespread species, because species close to the edge of their geographical ranges may be quite widespread in the study area but still locally rare (Gaston et al. 1997b). Our results did not support this prediction, indeed, the variance in carabid abundances was larger for less widespread species.

It is also worth noting that carabid species close to the edge of their ranges had small mean geographic ranges and low mean local abundances. This result

lends support for the generally observed pattern of decline in local abundances and lower patch occupancy of species towards the edges of their geographic ranges (Hengeveld and Haeck 1982, Lawton 1993, Gaston et al. 1997a).

\section{Resource breadth hypothesis is supported}

According to the resource breadth hypothesis (Brown 1984), species that exploit a variety of resources are more widespread. Our data supported this expectation as generalist carabid species (species with wide niche breadths occurring in a variety of habitat types) were significantly more widespread than specialists (species 
Table 6. Estimates of the effect sizes of the significant factors per country (see Table 5). SE = standard error.

\begin{tabular}{|c|c|c|c|c|c|c|}
\hline \multirow[b]{2}{*}{ Factor* } & \multicolumn{2}{|c|}{ Belgium } & \multicolumn{2}{|c|}{ Denmark } & \multicolumn{2}{|c|}{ Netherlands } \\
\hline & Estimate & SE & Estimate & SE & Estimate & SE \\
\hline Constant & -2.935 & 0.273 & -3.431 & 0.284 & -3.112 & 0.306 \\
\hline $\mathrm{H} \_\mathrm{N}-$ human & 0.330 & 0.110 & 0.199 & 0.110 & 0.378 & 0.120 \\
\hline Habitat - dry woodland & -0.005 & 0.223 & 0.048 & 0.235 & 0.082 & 0.270 \\
\hline Habitat - wet many & 0.284 & 0.174 & 0.120 & 0.236 & 0.429 & 0.196 \\
\hline Habitat - dry many & -0.108 & 0.155 & 0.120 & 0.207 & 0.042 & 0.175 \\
\hline Habitat - wet open & -0.051 & 0.260 & -0.038 & 0.303 & -0.126 & 0.265 \\
\hline Habitat - dry open & 0.086 & 0.184 & -0.084 & 0.236 & -0.066 & 0.210 \\
\hline Habitat - wet grassland & -0.273 & 0.256 & -0.295 & 0.403 & 0.142 & 0.303 \\
\hline Habitat - dry grassland & -0.676 & 0.188 & 0.007 & 0.212 & -0.520 & 0.221 \\
\hline Habitat - riparian & -0.141 & 0.169 & 0.237 & 0.188 & 0.317 & 0.184 \\
\hline Habitat - bogs & -0.459 & 0.500 & 0.150 & 0.354 & -0.336 & 0.414 \\
\hline Habitat - wet coastal & -1.359 & 0.326 & -0.001 & 0.222 & -0.031 & 0.242 \\
\hline Habitat - dry coastal & -1.781 & 0.932 & -0.075 & 0.369 & -0.740 & 1.080 \\
\hline Wings - macropterous & -0.079 & 0.140 & -0.196 & 0.144 & 0.342 & 0.172 \\
\hline Wings - dimorphic & -0.011 & 0.165 & 0.076 & 0.166 & 0.639 & 0.193 \\
\hline Size & 0.133 & 0.051 & 0.065 & 0.050 & 0.089 & 0.054 \\
\hline S_G & 0.429 & 0.039 & 0.429 & 0.042 & 0.498 & 0.043 \\
\hline
\end{tabular}

* Size and S_G are variates, so the effect is the regression coefficient. The factor level not mentioned is set to zero, i.e. the constant is equal to the levels $H_{-}$N 1 (i.e. natural environment), habitat 1 (i.e. wet woodland) and wings 3 (i.e. Brachypterous).

Table 7. Regression results with all factors regressed against log carabid abundance. The square root of Grids was used as a weight. Only the main effects are shown as most first, and all higher order interactions had small effects on the main model. The order in which the factors are entered into the model affects the analysis as most factors are correlated. Of particular interest here are the specialisation (S_G) ANOVA results (in bold) in testing Brown's resource breadth hypothesis (see text).

\begin{tabular}{|c|c|c|c|c|c|}
\hline Country and factor & $\mathrm{DF}$ & SS & MS & $\mathrm{F}$ & $\mathrm{p}$ \\
\hline \multicolumn{6}{|l|}{ Belgium } \\
\hline Grids & 1 & 20.664 & 20.664 & 215.797 & $<0.001$ \\
\hline N_H & 1 & 0.043 & 0.043 & 0.447 & 0.505 \\
\hline Habitat & 11 & 3.128 & 0.284 & 2.969 & $<0.002$ \\
\hline Wing form & 2 & 0.295 & 0.148 & 1.540 & 0.216 \\
\hline Body size & 1 & 0.007 & 0.007 & 0.069 & 0.793 \\
\hline S_G & 1 & 0.002 & 0.002 & 0.023 & 0.880 \\
\hline Residual & 246 & 23.556 & 0.096 & & \\
\hline \multicolumn{6}{|l|}{ Denmark } \\
\hline Grids & 1 & 0.564 & 0.564 & 41.381 & $<0.001$ \\
\hline N_H & 1 & 0.017 & 0.017 & 1.266 & 0.262 \\
\hline Hābitat & 11 & 0.264 & 0.024 & 1.765 & 0.062 \\
\hline Wing form & 2 & 0.131 & 0.065 & 4.790 & 0.009 \\
\hline Body size & 11 & 0.057 & 0.057 & 4.197 & 0.042 \\
\hline S_G & 1 & 0.006 & 0.006 & 0.421 & 0.517 \\
\hline Residual & 201 & 2.739 & 0.014 & & \\
\hline \multicolumn{6}{|l|}{ The Netherlands } \\
\hline Grids & 1 & 69.682 & 69.682 & 173.705 & $<0.001$ \\
\hline N_H & 1 & 3.103 & 3.103 & 7.736 & 0.006 \\
\hline Habitat & 11 & 20.819 & 1.893 & 4.718 & $<0.001$ \\
\hline Wing form & 2 & 10.470 & 5.235 & 13.050 & $<0.001$ \\
\hline Body size & 1 & 8.012 & 8.012 & 19.974 & $<0.001$ \\
\hline$S \_G$ & 1 & 5.277 & 5.277 & 13.154 & $<0.001$ \\
\hline Residual & 200 & 80.230 & 0.401 & & \\
\hline
\end{tabular}

Outlier species did not alter the results significantly.

with small niche breadths occurring in only one or two habitat types). Some studies have shown similar patterns in a range of animals including invertebrates (Kolasa et al. 1998), fish (Pyron 1999) and mammals (Eeley and Lawes 1999), contradicting conclusions of others (Hanski et al. 1993, Gaston et al. 1997b, Gregory and Gaston 2000). However, it is difficult to explain why generalist species should also be locally abundant (Gaston et al. 1997b). Intuitively, generalists should not be locally more abundant than specialists because this would imply that ecological specialisation has no advantages (Hanski et al. 1993).

Our Belgian and Danish data showed little change in mean abundance with specialisation once range size 
was taken into account, which appears to contradict the notion that there is a tendency for specialist species to be scarce, while generalist species have higher local population densities (Brown 1984, Taylor et al. 1993, Quinn et al. 1997). However, the relationship between range size and abundance was not controlled for, and it could be that specialist species were less numerous because they were less widespread. The problem here is that of inferring cause from correlation. Most analyses of the abundance-range size relationship have implicitly assumed that range size "causes" abundance (as abundance is regressed against range size), but in reality the relationship is probably more complicated. The two parts of the metapopulation hypothesis explicitly provide mechanisms by which abundance can affect range size, and vice versa (see Gaston et al. 1997b).

Carabid species found in anthropogenic environments tend to have broader environmental associations than species in natural habitats (Tables 5 and 6), which provides additional support to the resource breadth hypothesis (Gaston et al. 1997b).

To summarize, our data support the resource breadth hypothesis. We suggest that specialisation affects species range size, which in turn is related to abundance. Since there is considerable variation in abundance at low and intermediate range size, and because of the interdependence of local abundance and range size (Gaston 1990), specialisation and abundance are not always significantly correlated, once the effect of range size has been removed. However, abundance and range size are correlated, but it is not always clear which is cause and which is effect.

\section{Landscape change and the abundance-range size relationship}

Belgium, Denmark and the Netherlands have experienced a significant reduction, destruction and isolation of natural habitats, especially since the mid-20th century (Hengeveld 1985, Turin and Den Boer 1988, Desender and Turin 1989). These changes are important from a nature conservation point of view because geographically restricted species tend to have small local populations, making them vulnerable to extinction (Lawton 1993, Blackburn and Gaston 1998). For instance, range size and local abundance were more important determinants of marsupial extinction probability than differences in fecundity or body size (Johnson 1998). Also, threatened wildfowl species had small population and geographic range sizes (Gaston and Blackburn 1996).

In our study, specialist carabid species outnumbered generalists (Belgium 139 to 72 species; Denmark 96 to 69; the Netherlands 94 to 70) (see also Taylor et al. 1993), which indicates that a large num- ber of species is potentially vulnerable to habitat alterations. Indeed, 142 carabid species (nearly $34 \%$ of the species pool) are endangered in western Europe (Denmark, Netherlands, Belgium and Luxembourg), with a large proportion being habitat specialists, intolerant of agricultural intensification (Turin and Den Boer 1988, Desender and Turin 1989, Kotze and O'Hara 2003). The small number of species that favour human-altered environments, on the other hand, showed a significantly larger range size than those that are not associated with such habitats in our study.

Overall, habitat fragmentation will lead to range contraction of many species (Gaston 1990), but how this will influence local abundance is unclear. Hanski (1991) predicted that local abundance would decrease with increased isolation of habitat patches as a result of lower levels of migration. Isolated habitat patches will therefore have high extinction rates. The habitat selection hypothesis predicts that species that have undergone major reductions in total population abundance from density-independent events, such as fragmentation, will both have reduced ranges and occupy fewer habitats after the event. Examples to this effect are found in European carabids (Desender et al. 1999, Niemelä 2001). For instance, Carabus nitens L., which was once common in Europe's large heathland areas, is now threatened because of fragmentation and disappearance of this habitat type (Assmann and Janssen 1999). Even if suitable patches are available in some areas, the species may not be able to recolonise fragments that have once faced local extinction, indicating that fragmentation indeed has a negative effect on this species.

The effects of fragmentation may be further complicated by time lags between the fragmentation event and the subsequent extinction of a species, the "extinction debt" (Thompson et al. 1998, Hanski 2000). In our study, carabid species in the upper left-hand corner of the abundance-range size relationships may be in this situation, and be remnants of formerly widespread species that are now patchily distributed, due to habitat destruction, but still locally abundant.

Although many species might have experienced dramatic range contractions, others are increasing in range size and local abundance. The atlases indicated that $68(17.9 \%)$ Belgian species, $62(19.7 \%)$ Danish species and $73(19.2 \%)$ Dutch species are increasing in either range size or number of records. Examples include Pterostichus melanarius Ill., a generalist species increasing its range size in Europe (Turin 2000), and in North America where it has been introduced (Niemelä and Spence 1991). This and other examples suggest that ecological flexibility favours invasion ability, and lend further support for Brown's (1984) resource breadth hypothesis (Lawton 1993). 


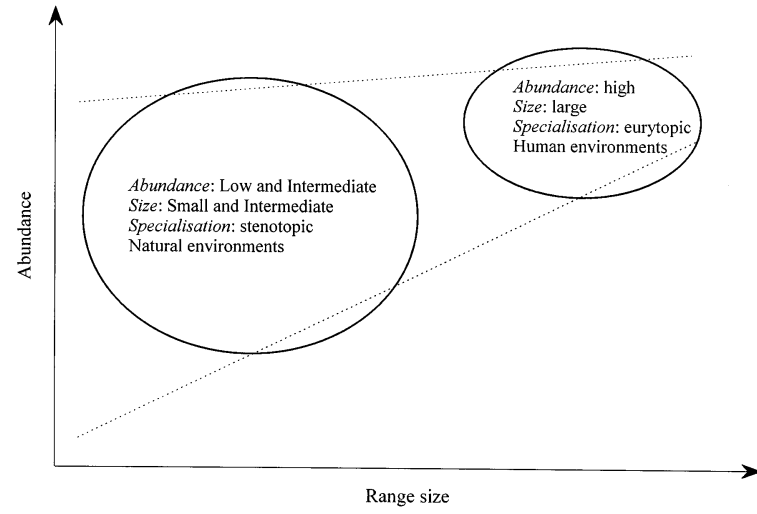

Fig. 5. A general, theoretical relationship between abundance and range size for carabids in northern Europe.

\section{Conclusions}

According to the triangular relationship between abundance and range size proposed by Gaston (1994, 1996) and Eeley and Lawes (1999), maximum density increases with increasing range size and, while no species occupy a small range and have high density, widespread species may occur at either a high or low density. This relationship is somewhat surprising as one would expect at least some habitat specialists to be geographically restricted, but locally abundant (Rabinowitz et al. 1986, Hanski et al. 1993). Indeed, for the perennial herbaceous flora of central England, Thompson et al. (1998) showed that widespread species are almost always abundant where they occur whilst more restricted species showed considerable variation in local abundance. Our carabid data also show this pattern.

Finally, in our data widespread species are usually larger, habitat generalists and are associated with human-modified habitats. Restricted and intermediately distributed species, on the other hand, are smaller in size, more specialised, and are mainly found in natural environments. These conclusions can be summarized in a chart (Fig. 5).

Acknowledgements - We thank Daniel Simberloff, Robert Colwell, John Spence, Lyubomir Penev and Jonathan Sadler for valuable comments. Jacob Tennis helped with data collecting from the literature. This is a contribution from the Finnish Biodiversity Research Programme project no. 39715.

\section{References}

Assmann, T. and Janssen, J. 1999. The effects of habitat changes on the endangered ground beetle Carabus nitens (Coleoptera: Carabidae). - J. Insect Conserv. 3: 107-116.

Bangsholt, F. 1983. Sandspringernes og løbebillernes udbredelse og forekomst i Denmark ca. 1830-1981 (Coleoptera: Cicindelidae and Carabidae). - Dansk faunistik Bibliotek 4, København.

Blackburn, T. M. and Gaston, K. J. 1998. Some methodological issues in macroecology. - Am. Nat. 151: 68-83.
Blackburn, T. M. et al. 1997. Of mice and wrens: the relation between abundance and geographic range size in British mammals and birds. - Philos. Trans. R. Soc. Lond. B 352: $419-427$.

Blackburn, T. M. et al. 1999. Do local abundances of British birds change with proximity to range edge? - J. Biogeogr. 26: $493-505$

Brown, J. H. 1984. The relationship between abundance and distribution of species. - Am. Nat. 124: 255-279.

Brown, J. H. 1995. Macroecology. - Univ. of Chicago Press.

Dempster, A. P. Laird, N. M. and Rubin, D. B. 1977. Maximum likelihood from incomplete data via the EM algorithm (with discussion). - J. R. Stat. Soc. B 39: 1-38.

Dennis, R. L. H. and Thomas, C. D. 2000. Bias in butterfly distribution maps: the influence of hot spots and recorder's home range. - J. Insect Conserv. 4: 73-77.

Desender, K. 1986a, b, c, d. Distribution and ecology of carabid beetles in Belgium (Coleoptera, Carabidae), Part 1, 2, 3, 4. - Inst. Roy. des Sci. Nat. de Belgique. Documents de Travail 26: 1-30; 27: 1-24; 30: 1-23; 34: 1-48.

Desender, K. and Turin, H. 1989. Loss of habitats and changes in the composition of the ground and tiger beetle fauna in four west European countries since 1950 (Coleoptera: Carabidae: Cicindelidae). - Biol. Conserv. 48: 277-294.

Desender, K., Ervynck, A. and Tack, G. 1999. Beetle diversity and historical ecology of woodlands in Flanders. - Belg. J. Zool. 129: 139-156.

Draper, N. R. and Smith, H. 1998. Applied regression analysis. - Wiley.

Dufrêne, M. and Legendre, P. 1997. Species assemblages and indicator species: the need for a flexible asymmetrical approach. - Ecol. Monogr. 67: 345-366.

Durrer, S. and Schmid-Hempel, P. 1995. Parasites and the regional distribution of bumblebee species. - Ecography 18: $114-122$

Eeley, H. A. C. and Lawes, M. J. 1999. Large-scale patterns of species richness and species range size in anthropoid primates. - In: Fleagle, J. G., Janson, C. H. and Reed, K. E. (eds), Primate communities. Cambridge Univ. Press, pp. $191-219$.

Gaston, K. J. 1990. Patterns in the geographical ranges of species. - Biol. Rev. 65: 105-129.

Gaston, K. J. 1991. How large is a species' geographic range size. - Oikos 61: 434-438.

Gaston, K. J. 1994. Rarity. - Chapman and Hall.

Gaston, K. J. 1996. The multiple forms of the interspecific abundance-distribution relationship. - Oikos 76: 211220

Gaston, K. J. and Lawton, J. H. 1990. Effects of scale and habitat on the relationship between regional distribution and abundance. - Oikos 58: 329-335.

Gaston, K. J. and Blackburn, T. M. 1996. Global scale macroecology: interactions between population size, geographic range size and body size in the Anseriformes. - J. Anim. Ecol. 65: 701-714.

Gaston, K. J., Blackburn, T. M. and Gregory, R. D. 1997a. Interspecific abundance-range size relationships: range position and phylogeny. - Ecography 20: 390-399.

Gaston, K. J., Blackburn, T. M. and Lawton, J. H. 1997 b. Interspecific abundance-range size relationships: an appraisal of mechanisms. - J. Anim. Ecol. 66: 579-601.

Gaston, K. J., Blackburn, T. M. and Lawton, J. H. 1998. Aggregation and interspecific abundance-occupancy relationships. - J. Anim. Ecol. 67: 995-999.

Gregory, R. D. and Blackburn, T. M. 1998. Macroecological patterns in British breeding birds: covariation of species' geographical range size at differing spatial scale. - Ecography 21: $527-534$.

Gregory, R. D. and Gaston, K. J. 2000. Explanations of commonness and rarity in British breeding birds: separating resource use and resource availability. - Oikos 88: $515-526$. 
Griffiths, D. 1998. Sampling effort, regression method, and the shape and slope of size-abundance relations. - J. Anim. Ecol. 67: 795-804.

Hanski, I. 1991. Reply to Nee, Gregory and May. - Oikos 62: $88-89$.

Hanski, I. 2000. Extinction debt and species credit in boreal forests: modelling the consequences of different approaches to biodiversity conservation. - Ann. Zool. Fenn. 37: 271280.

Hanski, I., Kouki, J. and Halkka, A. 1993. Three explanations of the positive relationship between distribution and abundance of species. - In: Ricklefs, R. E. and Schluter, D. (eds), Species diversity in ecological communities. The Univ. of Chicago Press, pp. 108-116.

Harvey, P. H. and Pagel, M. D. 1991. The comparative method in evolutionary ecology. - Oxford Univ. Press.

Hengeveld, R. 1985. Dynamics of Dutch beetle species during the twentieth century (Coleoptera, Carabidae). - J. Biogeogr. 12: 389-411.

Hengeveld, R. and Haeck, J. 1982. The distribution of abundance. I. Measurements. - J. Biogeogr. 9: 303-316.

Högmander, H. and Møller, J. 1995. Estimating distribution maps from atlas data using methods of statistical image analysis. - Biometrics 51: 393-404.

Johnson, C. N. 1998. Species extinction and the relationship between distribution and abundance. - Nature 394: 272274.

Kolasa, J., Hewitt, C. L. and Drake, J. A. 1998. Rapoport's rule: an explanation or a byproduct of the latitudinal gradient in species richness? - Biodiv. Conserv. 7: 1447-1455

Kotze, D. J. and O'Hara, R. B. 2003. Species decline - but why? Explanations of carabid beetle (Coleoptera, Carabidae) declines in Europe. - Oecologia 135: 138-148.

Lawton, J. H. 1993. Range, population abundance and conservation. - Trends Ecol. Evol. 8: 409-413.

Lawton, J. H. 1994. Population dynamic principles. - Philos. Trans. R. Soc. Lond. B 344: 61-68.

Lindroth, C. H. 1985. The Carabidae (Coleoptera) of Fennoscandia and Denmark. - Fauna Entomol. Scand. 15, part 1. Scand. Sci. Press, Copenhagen.

Lindroth, C. H. 1986. The Carabidae (Coleoptera) of Fennoscandia and Denmark. - Fauna Entomol. Scand. 15, part 2. Scand. Sci. Press, Copenhagen.

Lövei, G. L. and Sunderland, K. D. 1996. Ecology and behavior of ground beetles (Coleoptera: Carabidae). - Annu. Rev. Entomol. 41: 231-256.

Maddison, D. R., Baker, M. D. and Ober, K. A. 1999 Phylogeny of carabid beetles as inferred from $18 \mathrm{~S}$ ribosomal DNA (Coleoptera: Carabidae). - Syst. Entomol. 24: 103138.
McCullagh, P. and Nelder, J. A. 1989. Generalized linear models, 2nd ed. - Chapman and Hall.

Niemelä, J. 2001. Carabid beetles (Coleoptera, Carabidae) and habitat fragmentation: a review. - Eur. J. Entomol. 98: $127-132$.

Niemelä, J. and Spence, J. R. 1991. Distribution and abundance of an exotic ground beetle (Carabidae): a test of community impact. - Oikos 62: 351-359.

Poulin, R. 1999. The intra- and interspecific relationships between abundance and distribution in helminth parasites of birds. - J. Anim. Ecol. 68: 719-725.

Pyron, M. 1999. Relationships between geographical range size, body size, local abundance, and habitat breadth in North American suckers and sunfishes. - J. Biogeogr. 26: 549-558.

Quinn, R. M. et al. 1997. Abundance-range size relationships of macrolepidoptera in Britain: the effects of taxonomy and life history variables. - Ecol. Entomol. 22: 453461 .

Rabinowitz, D., Cairns, S. and Dillon, T. 1986. Seven forms of rarity and their frequency in the flora of the British Isles. In: Soulé, M. E. (ed.), Conservation biology: the science of scarcity and diversity. Sinauer, pp. 182-204.

Sampford, M. R. 1955. The truncated negative binomial distribution. - Biometrika 42: 58-69.

Simpson, G. G. 1964. Species density of North American recent mammals. - Syst. Zool. 13: 57-73.

Taylor, C. M., Winston, M. R. and Matthews, W. J. 1993. Fish species-environment and abundance relationships in a Great Plains river system. - Ecography 16: 16-23.

Thiele, H.-U. 1977. Carabid beetles in their environments. Springer.

Thompson, K., Hodgson, J. G. and Gaston, K. J. 1998. Abundance-range size relationships in the herbaceous flora of central England. - J. Ecol. 86: 439-448.

Turin, H. 2000. De Nederlandse Loopkevers, Verspreiding en Oecologie (Coleoptera: Carabidae). - Nederlandse Fauna 3. Nationaal Natuurhistorisch Museum Naturalis, KNNV Uitgeverij and EIS-Nederland, Leiden.

Turin, H. and Den Boer, P. J. 1988. Changes in the distribution of carabid beetles in the Netherlands since 1880. II. Isolation of habitats and long-term trends in the occurrence of carabid species with different powers of dispersal (Coleoptera, Carabidae). - Biol. Conserv. 44: 179-200

Turin, H. and Heijerman, T. 1988. Ecological classification of forest-dwelling Carabidae (Coleoptera) in the Netherlands. - Tijdschrift Entomol. 131: 65-71.

Venables, W. N. and Ripley, B. D. 1999. Modern applied statistics with S-PLUS, 3rd ed. - Springer. 